\title{
The Impact of the Vane Angle on the Hydraulic Behaviour Around the Cylinder
}

\author{
Tahseen Ali Jabbar ${ }^{1}$, Rafi M.Qasim ${ }^{2}$, Bassam A. Mohammed $^{3}$ \\ \{tahseen.ali@stu.edu.iq ${ }^{1}$, rafi.mohammed@stu.edu.iq ${ }^{2}$, bassam.moh@stu.edu.iq $\left.{ }^{3}\right\}$ \\ 1,2 Department of Fuel and Energy, Southern Technical University, Basra, Iraq. \\ 3 Department of thermal mechanical, Southern Technical University, Basra, Iraq
}

\begin{abstract}
The flow around an obstacle represents a challenge in fluid mechanics problems and practice. So, it is significant to investigate the hydraulic behaviour around the obstacle and the response of the obstacle which encounters the flow suddenly. The target of the present paper deal with the investigation numerically the effect of changing the vane angle on the hydraulic field around the cylinder and the response of the cylinder to the angle change. The vane has an angle shape with different angles ranging from 20 degrees to 90 degrees, the dimension of the angle is adopted as a function of the cylinder diameter. The study concentrates on the average flow velocity, strain rate, shear stress, static pressure, dynamic pressure, pressure coefficient, skin friction coefficient, drag coefficient, and lift coefficient. The obtained result shows a noticeable variation in the response of the hydraulic field around the cylinder especially in average flow velocity, static pressure, dynamic pressure, strain rate, and shear stress. The negative lift coefficient and negative drag coefficient appear in the numerical investigation. Also, a negative pressure coefficient is found. Many reasons will lead to the negative response like pressure difference from section to section, changing inflow velocity owing to the existence of the vane in addition to the cylinder, flow separation zone expansion, flow velocity dissipation owing to the existence of the vane, momentum transfer from section to section and turbulence level.
\end{abstract}

Keywords: Cylinder, flow field, turbulent flow, vane angle.

\section{Introduction}

A turbulent hydraulic flow field around a circular body like piers, piles, and pipes is considered as a significant and noticeable problem in fluid mechanics and hydraulic structure design consideration, especially in the subject of the, scour around bridge pier and pile, therefore, many papers deal with this subject from the previous time to present to find a suitable solution and avoid any hydraulic problem which reflects on the flow field - structure interaction. Catalano et al. (2003) [1] studied the turbulent flow around a circular in the supercritical regime at high Reynolds numbers. The large eddy simulation is adopted in the study and compared with the Reynolds- average Navier-Stokes Solution. Based on the obtained result the large eddy simulation was significantly more accurate as compared with Reynolds-average Navier-Stokes. Rajani et al. (2009) [2] dealt with the three-and two-dimensional flow which passes a cylinder with a circular section in various regimes of laminar flow. The analysis concentrated on the 
verification between the measured data and the computational result. Singha et al. (2010) [3] investigated numerically the flow around a cylinder with a circular section placed centrally inside a channel. The blockage ratio is studied by change the distance between the walls of the channel. The investigation concentrated on vortex shedding, wake pattern, drag coefficient, lift coefficient, and strouhal number. Ashtiani et al. (2013) [4] made a comparison between flow field around a single pier and tandem piers set up on a laboratory flume with a moderately flat rough bed. The flow velocities were measured by an Acoustic Doppler Velocimeter. The contours of the turbulent intensity, turbulent kinetic energy, velocity components, and Reynold shear stress are studied. Vectors and streamlines are adopted to study the flow features. Yagmur et al. (2015) [5] investigated numerically and experimentally the flow pattern in the wake region of various bluff bodies like a triangle, square and circular cross-section of cylinders placed horizontally and perpendicularly to the flow. The experimental work is carried out in an open channel at water Reynolds numbers 10000 and 5000. While the numerical analysis is performed by ANSYS Fluent software. Elbatran (2016) [6] made a three-dimensional numerical study to reveal the turbulent flow characteristics around a cylinder which has a circular section. A detached eddy simulation model with a Reynolds number equal to 43000 is adopted in the numerical study. The obtained numerical result was compared with experiments and theoretical results found by the other researchers. Khassaf and Obied (2018) [7] carried out an experimental study to investigate the impact of the guide panels on local scour which happens around the bridge pier. They found from the experiments as the panel height decrease, the scour depth has been decreased. Abdulhussein et al (2019) [8] performed an experimental study to reveal the impact of the strip guide flow panel on local scour which occurs around the pier. They obtained from the experiments; the use of the strip guide reduces the scour depth. Here the guide is mounted upstream of the pier. Marelius and Sinha (1998) [9] investigated numerically and experimentally the flow velocity profile around the submerged vanes. The paper's purpose concentrates on the impact of vane angle influence on the altered hydraulic flow pattern around a cylinder. Here, the vane is installed upstream of the cylinder. The numerical study includes the investigation of the following average flow velocity, strain rate, shear stress, drag coefficient, lift coefficient, skin friction coefficient, pressure coefficient, static pressure, and dynamic pressure.

\section{Numerical Modelling}

The problem is considered in two dimensions. Here, the water flow passes the vane and then passes the cylinder at Reynolds number 18094.8. The problem is modelled and simulated by ANSYS Fluent software. Fig 1 illustrates the dimension of the water domain which includes the vane and the cylinder. Here, the vane is placed upstream of the cylinder, while Fig 2 illustrates the fine mesh with numbers of the element (42000 elements). The water is the flow material and is considered an incompressible material with a density of $998.2 \mathrm{Kg} / \mathrm{m}^{3}$ and viscosity $0.001003 \mathrm{Kg} / \mathrm{m}$.s . The boundary condition of the hydraulic system is given in table (1). The bed of the channel is considered horizontal, fixed, and flat. The vane angle adopted in the study has a range between $30^{\circ}$ and $90^{\circ}$ with an angle interval equal to $5^{\circ}$. The time which is used to achieve the numerical analysis is 8 seconds. 


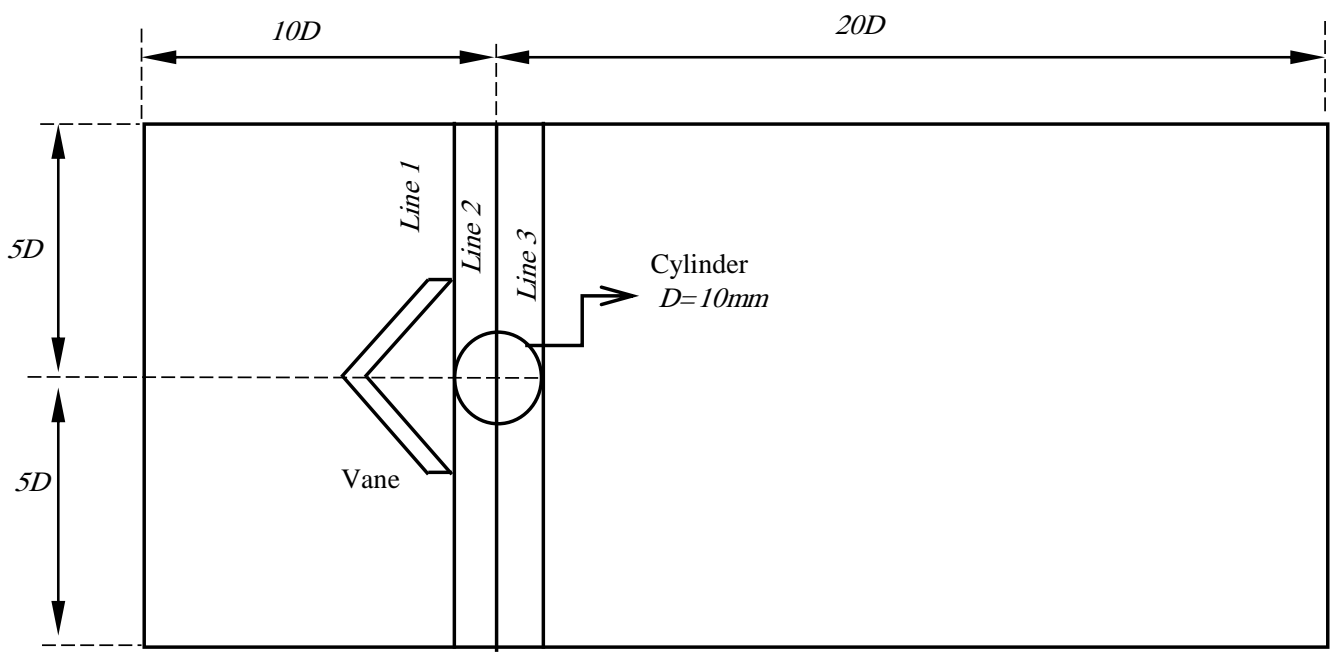

(a)

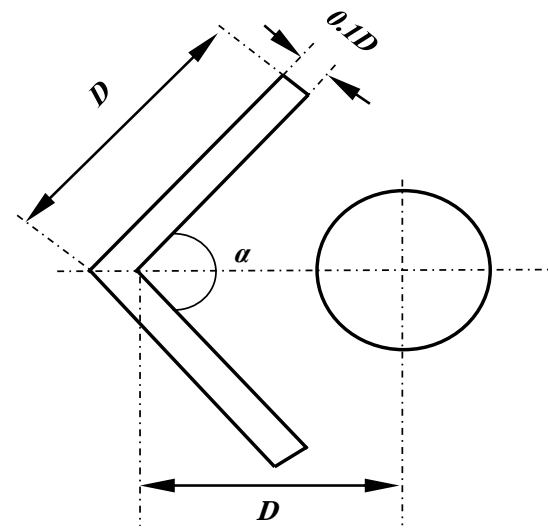

(b)

Fig. 1. Shows the hydraulic system components with hydraulic domain (a) full domain (b) the vane and cylinder.

Table 1. Boundary condition of the hydraulic system.

\begin{tabular}{ll}
\hline Inlet & Velocity at inlet \\
\hline Outlet & Pressure at outlet \\
Cylinder & No slip-Wall \\
Vane & No slip-Wall \\
Channel bed & No slip-Wall
\end{tabular}


Channel sides

Top surface of flow
No slip-Wall

Atmospheric Pressure

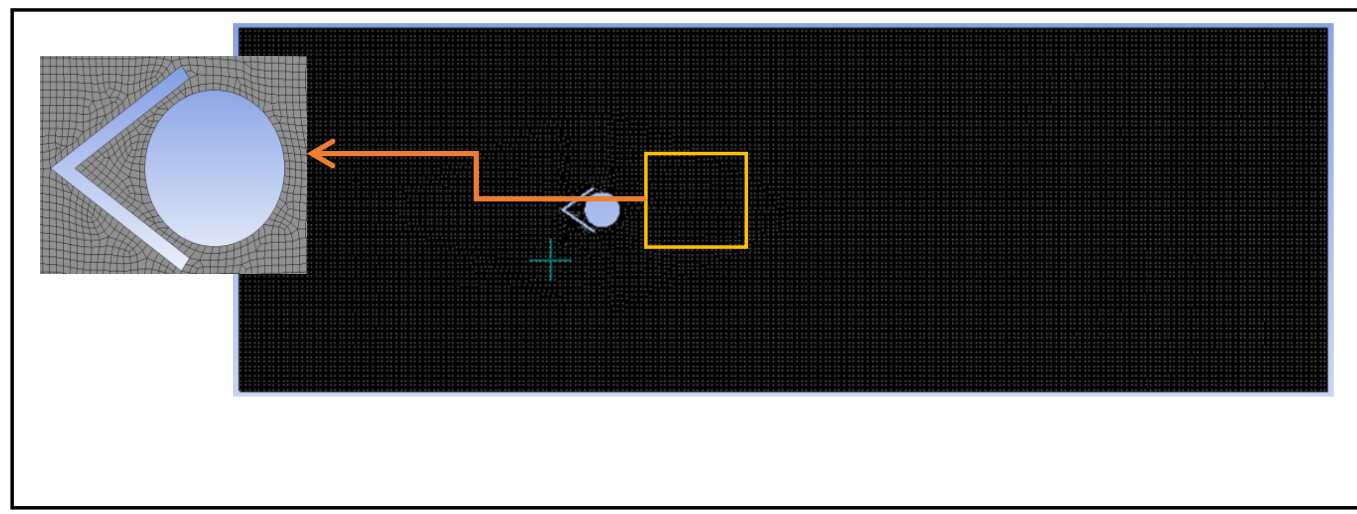

Fig. 2. The mash of the model (42000 elements).

The CFD governing equations that will be used for the simulation are the conservation of momentum equation and incompressible fluid continuity equation are shown in equations (1) to (4), respectively.

$$
\begin{aligned}
& u \frac{\partial u}{\partial x}+v \frac{\partial u}{\partial y}+w \frac{\partial u}{\partial z}=-\frac{1}{\rho} \frac{\partial P}{\partial x}+\frac{\mu}{\rho}\left(\frac{d^{2} u}{d x^{2}}+\frac{d^{2} u}{d y^{2}}+\frac{d^{2} u}{d z^{2}}\right) \\
& u \frac{\partial v}{\partial x}+v \frac{\partial v}{\partial y}+w \frac{\partial v}{\partial z}=-\frac{1}{\rho} \frac{\partial P}{\partial y}+\frac{\mu}{\rho}\left(\frac{d^{2} v}{d x^{2}}+\frac{d^{2} v}{d y^{2}}+\frac{d^{2} v}{d z^{2}}\right) \\
& u \frac{\partial w}{\partial x}+v \frac{\partial w}{\partial y}+w \frac{\partial w}{\partial z}=-\frac{1}{\rho} \frac{\partial P}{\partial z}+\frac{\mu}{\rho}\left(\frac{d^{2} w}{d x^{2}}+\frac{d^{2} w}{d y^{2}}+\frac{d^{2} w}{d z^{2}}\right) \\
& \frac{\partial(\rho u)}{\partial x}+\frac{\partial(\rho v)}{\partial y}+\frac{\partial(\rho w)}{\partial z}=0
\end{aligned}
$$

\subsection{Fluent verification}

It is important to verify the software before using it, to analyse the present problem, therefore, the fluent software is used to implement the case study in reference [10] and the obtained results have been compared with results that have been obtained in the reference (10). Reference (10) dealt with the analysis of the flow pattern around a pier which has a square cross-section in three dimensions. Table (2) review the detail of case study in reference [10] while table (3) review the comparison between the drag coefficient value which obtained from the present analysis and the drag coefficient value which given in reference [10]. 
Table 2. reference [10] case study details.

\begin{tabular}{clccc}
\hline $\mathrm{D}(\mathrm{m})$ & $\mathrm{V}(\mathrm{m} / \mathrm{s})$ & $\mathrm{H}(\mathrm{m})$ & $\rho(\mathrm{kg} / \mathrm{cu} . \mathrm{m})$ & $\mathrm{Re}$ (no unit) \\
1 & 0.292 & 2 & 1.225 & 20000 \\
\hline \multicolumn{5}{c}{ Table 3. comparison between present and previous study respectively. } \\
\hline Reference studies & Reynolds Number & Setup & & $C_{d}$ \\
Zaid et al. (10) & 20000 & Numerical & 2.1951 & \\
Present study & 20000 & Numerical & 2.15 & \\
\hline
\end{tabular}

\subsection{Mesh Independent}

The velocity of the fluid has a great influence on the properties of the flow, so the mesh independence was adopted on the average velocity at three different Lines. Fig 3 shows that the average velocity value of these Lines remains constant when the number of elements is greater than 30000 .

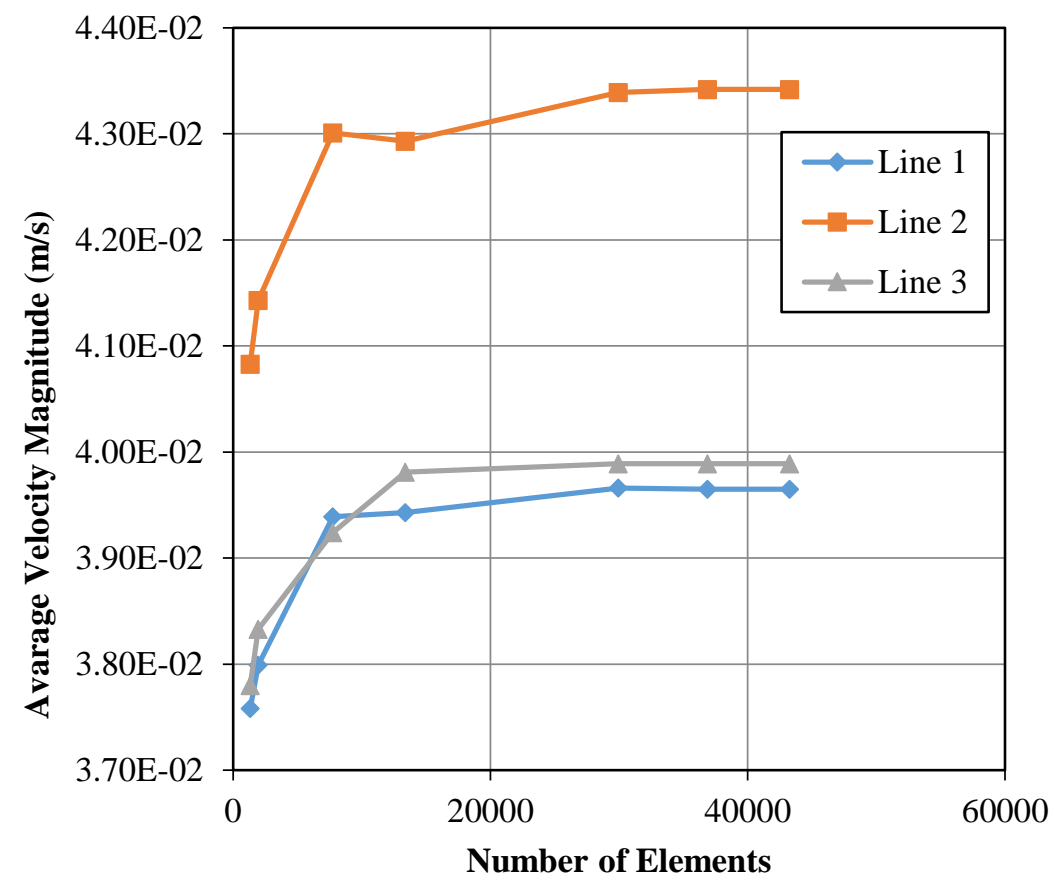

Fig. 3. Show the mesh independently. 


\section{Result and discussion}

The numerical investigation is done by ANSYS software and concentrated on some hydraulic variables which are discussed below. The variation of the average flow velocity with a variation of the vane angle is shown in Fig 4 . The variation is drawn at three lateral lines where the line (2) pass at the centre of the cylinder while the lines (1) and (3) passes at the edge of the cylinder. The variation of the average flow velocity at the centre of the cylinder (line 2 ) is higher as compared with the variation at the edge of the cylinder (lines 1 and 3). It is clear from the Fig the variation at line 1 and line 3 is approximately identical. Fig reveal when the vane angle increase, this led to an increase in average flow velocity variation especially at line 2 with a noticeable fluctuation at line 1 and line 3 and it is observed clearly at angle 60 degrees. Fluctuation depends on the flow separation zone, change in turbulence level, and water flow confinement at the vane. Here all these hydraulic variables dominate the magnitude of the flow velocity variation. Also, the vane shares inflow velocity dissipation.

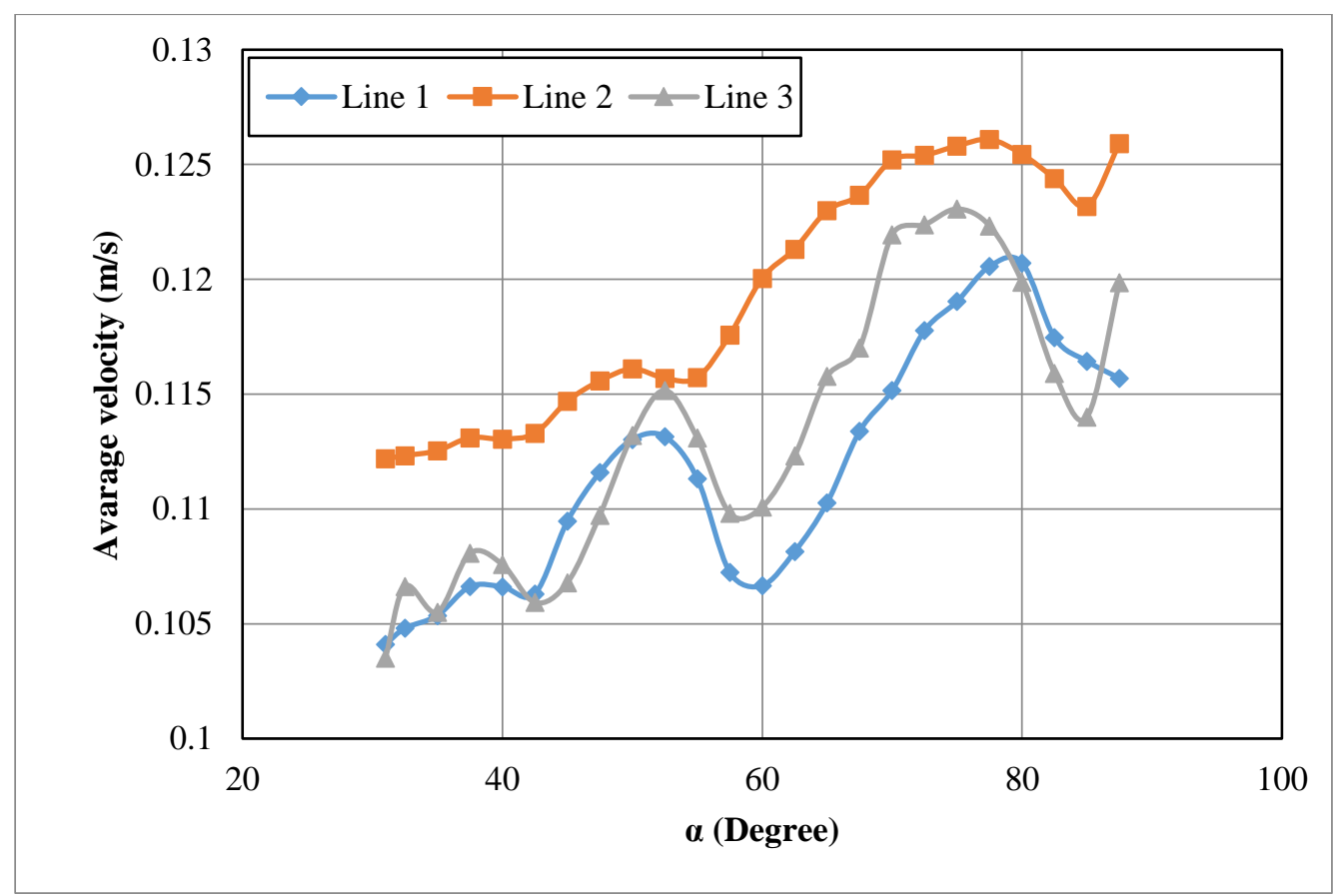

Fig. 4. variation of the average velocity with vane angle.

Fig 5 consists of two parts, the first one shows the relationship between drag coefficient and vane angle while the second shows the relationship between the lift coefficient and vane angle. it is very strange to shows the values of lift and drag coefficient respectively have a negative sign but at the same time there is no law or principle encourage to avoid the negative sign. It is observed from the figure a dramatically altered in values of drag and lifts coefficient respectively with the altered in the vane angle. expansion of flow separation zone, boundary layer growth, and development, the difference in pressure field around the vane and the cylinder, the interaction between the flow velocity field around the vane and the cylinder and the change 
in momentum transfer between the vane and the cylinder, all these variables will create and encourage to develop the negative lift and drag coefficient respectively.

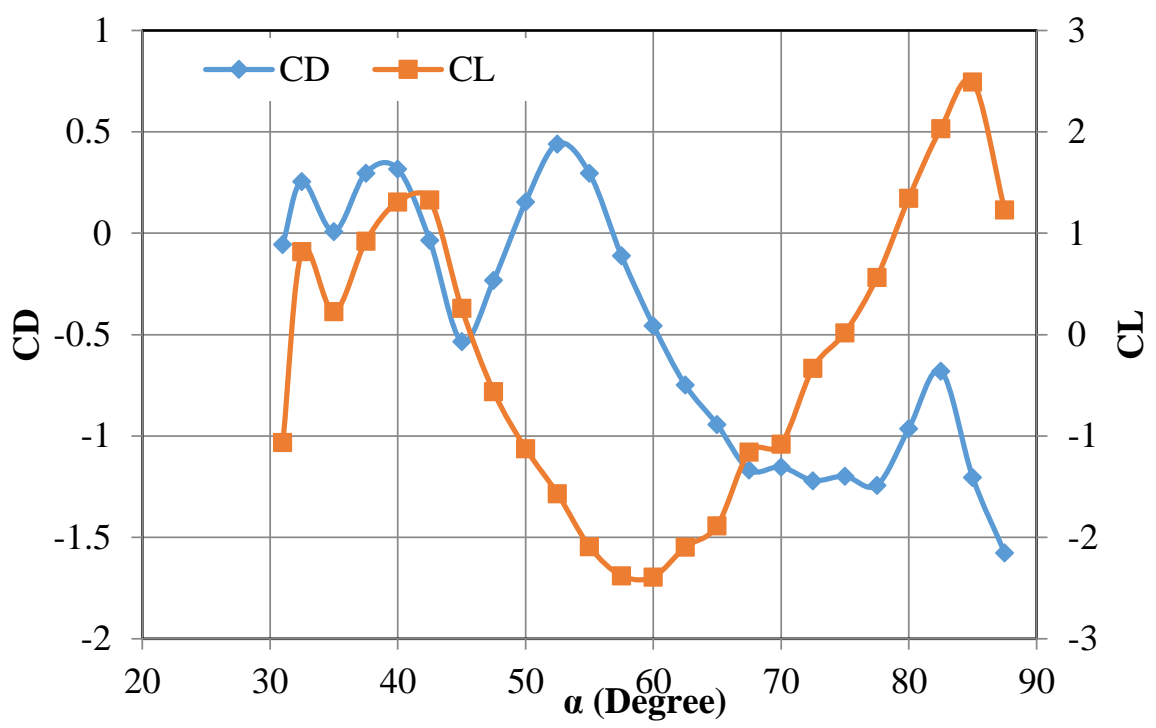

Fig. 5. variation of the drag coefficient and lift coefficient with the vane angle.

Fig 6 shows the variation of the static pressure and the dynamic pressure with the vane angle. It is obvious from the figure, the static pressure decreases with an increase in the vane angle, while the dynamic pressure increases with an increase in the vane angle. For both cases, pressure is more affected by the flow separation zone, stagnation points where the pressure is zero, the turbulence level, and the flow confinement by the vane, especially in static pressure.

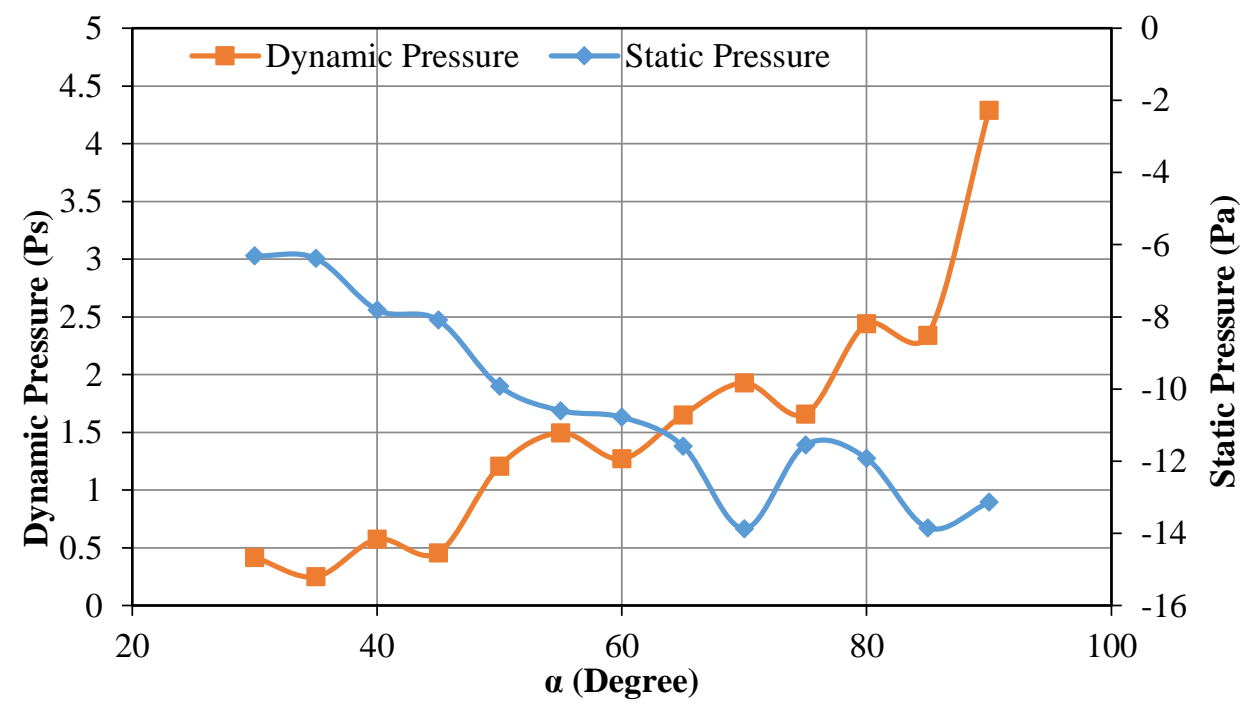

Fig. 6. Variation of the static pressure and the dynamic pressure with the vane angle. 
Fig 7 illustrates the relationship between the skin friction coefficient with the vane angle. It is clear from the figure; the skin friction coefficient increases with the increase in the vane angle values. Skin friction refers to the drag between the water flow and surface area. In general, the presence of the vane leads to reduce the water flow velocity, and as the flow velocity decreases the skin friction coefficient which grows at the cylinder surface will be increased. In addition to the shear stress which grows around the cylinder will reduce the flow velocity and increase the skin friction coefficient.

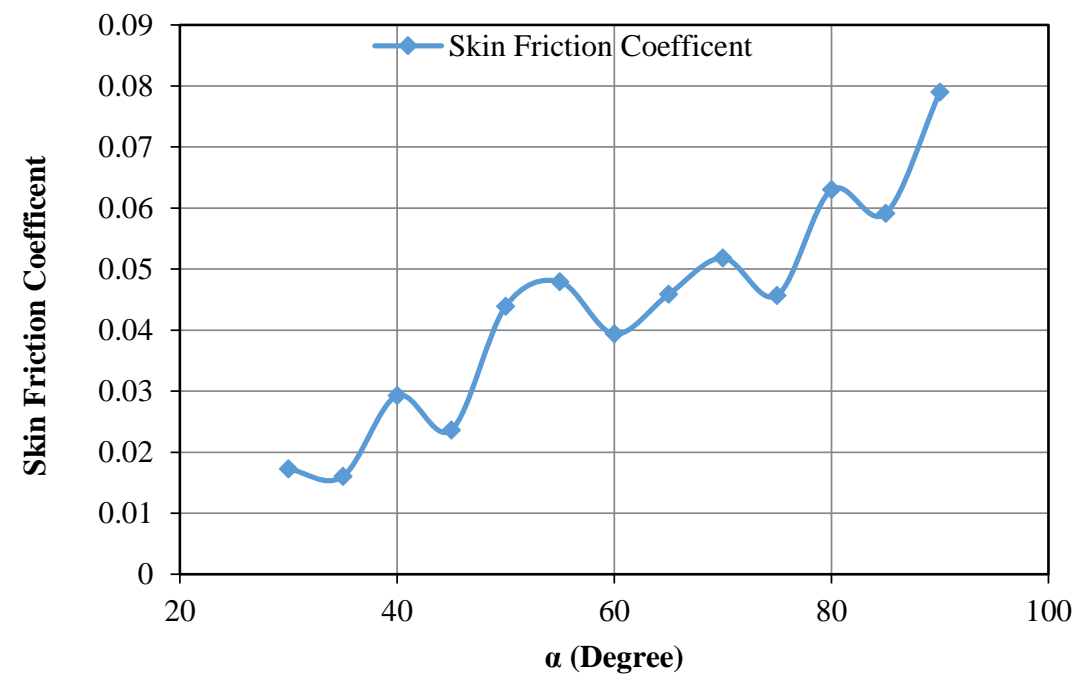

Fig. 7. Variation of the skin friction coefficient with the vane angle.

Fig 8 consists of two parts, the first one shows the relationship between strain rate and vane angle while the second shows the relationship between the shear stress and vane angle. It is obvious from the figure that both variables increase with increasing the vane angle. The flow velocity gradient and the flow momentum exchange between the downstream of the vane and the upstream of the cylinder will be reflected on the trend of the relationship. Also, the flow separation by the vane, the flow dissipation by the vane, and the turbulence level will be reflected on the relationship directly. 


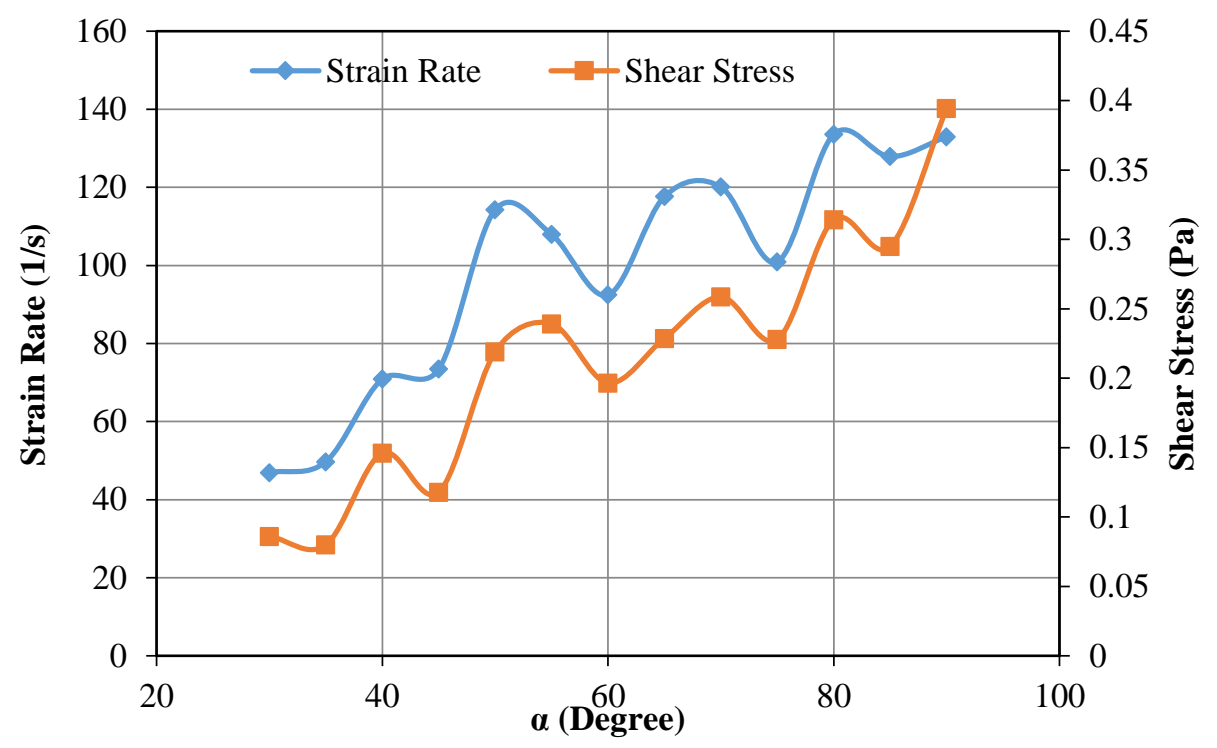

Fig. 8. Show the variation in strain rate and shear stress respectively with the vane angle.

Fig 9 illustrates the relationship between the pressure coefficient and the vane angle. The figure refers to the negation pressure coefficient. It is clear from the figure; the pressure coefficient decreases with an increase in the vane angle values. The change in vain angle leads to the change in the pressure around the cylinder or in other words leads to the difference between the upstream pressure and downstream pressure around the cylinder. So, this difference will lead to a negative pressure coefficient. Also, the pressure coefficient will be influenced by flow separation, flow velocity, and turbulence level.

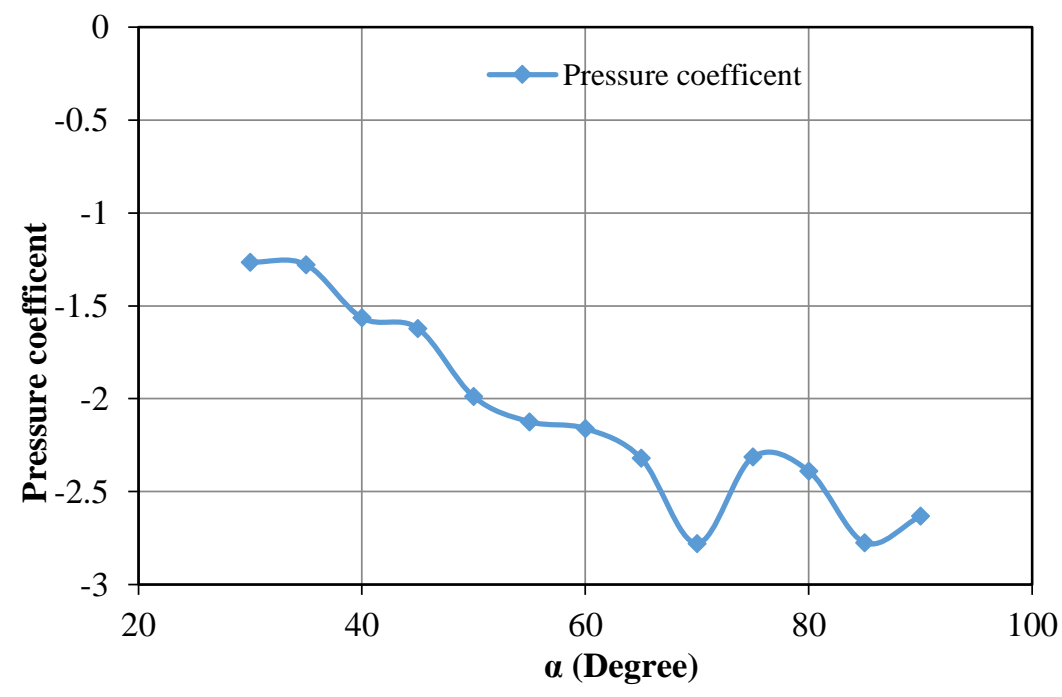

Fig. 9. Shows the variation in pressure coefficient with the vane angle. 


\section{Conclusion}

The following noticeable point can be considered from the current numerical study.

1. The vane angle controls the hydraulic interaction between the flow field around the cylinder and the flow field around the vane.

2. The negative lift coefficient and negative drag coefficient appear owing to change in pressure, momentum transfer, flow separation, and level of turbulence.

3. Skin friction is affected by the flow velocity in the region between the vane and the cylinder.

4. The velocity gradient has a direct effect on the strain rate and shear stress.

5. The difference in pressure between the upstream of the cylinder and the downstream of the cylinder has a major effect on the pressure coefficient.

6. Turbulence level, pressure difference, flow separation has a major effect on the static and dynamic pressure respectively.

7. The vane angle has a major role in control the variation of the average flow velocity at different functions.

\section{References}

[1] Catalano, P., Wang, M., Iaccarino G., Moin, P "Nmerical simulation of the flow around a circular cylinder at high Reynolds numbers" International Journal of Heat and Fluid Flow 24 (2003) 463-469.

[2] Rajani, B., N., Kandasamy, A., Majumdar, S.” Numerical simulation of laminar flow past a circular cylinder" Applied Mathematical Modelling 33 (2009) 1228-1247.

[3] Singha, S., Sinhamahapatra, K., P." Flow past a circular cylinder between parallel walls at low Reynolds numbers" Ocean Engineering 37 (2010) 757-769.

[4] Ashtiani, B., A., Kordkandi, A., A., "Flow field around single and tandem piers" Flow Turbulence Combust (2013) 90: 471-490.

[5] Yagmur, S., Dogan, S., Aksoy, M., H., Canli, E., Ozgoren, M.” Experimental and numerical investigation of flow structures around cylindrical bluff bodies" EPJ Web of Conferences 92, 02113 (2015).

[6] Elbatran, A., H." DES of the turbulent flow around a circular cylinder of finite height" Journal of Naval Architecture and Marine Engineering. 13(2016) 179-188.

[7] Khassaf, S., I., Obied, N., A.” Experimental study: bridge pier protection against local scour using guide panels" IOP Conf. Series: Materials Science and Engineering 433 (2018) 012006 doi:10.1088/1757899X/433/1/012006.

[8] Abdulhussein IA, Al-Asadi K, Qasim RM "Pier scouring reduction using a Strip Guide Flow Panel device" RUDN Journal of Engineering Researches. 2019;20(3):229-235.

[9] Marelius, F., and Sinha, S., K. "Experimental investigation of flow past submerged vanes" J. Hyd. Eng., ASCE, 1998, 124(5): 542-545.

[10] Zaid M., Yazdanfar Z., Chowdhury H., Alam F., "Numerical modeling of flow around a pier mounted in a flat and fixed bed" Energy Procedia, 160: 51-59, 2019. 